\title{
AN EXAMINATION OF RISK PROPENSITIES IN AN ORGANIZATIONAL CONTEXT: DIFFERENCES BY DISCIPLINE AND POSITION
}

\author{
Michael R. Walls \\ Division of Economics and Business \\ Colorado School of Mines \\ Golden, Colorado 80401, USA
}

\begin{abstract}
Previous studies of risk-taking suggest there are significant variations across individuals' willingness to take financial risk within the organizational context. For example, a decision maker's propensity to take risk may be more aligned with his unique planning horizon within the firm rather than the corporation's planning horizon. Previous research also suggests that division and lower level managers are typically more risk averse than top managers in the organization. In this case study we investigate differences in risk propensity across managerial and functional designations in a major oil company, BP Exploration, Inc. We present a model for measuring risk propensity, examine the results of a survey of 39 staff and supervisory personnel, and explore the implications of a divergence between individual risk propensities and the firm's corporate risk policy.
\end{abstract}

\section{INTRODUCTION}

The study of individual decision making under conditions of uncertainty has attracted much attention through most of this century. In recent years, the role of risk and uncertainty in organizations has gained increased recognition as the consequences of risky decisions have become more visible. Studies and findings associated with risk-taking behaviors within organizations has led to increased interest in the question of an appropriate risk policy for the firm. This study utilizes a decision analysis and expected utility theory model to help understand the risk-taking 
behavior of individuals in the organizational context. Implications for researchers and other individuals concerned with corporate risk management are discussed.

The von Neumann and Morgernstern [1] theory of expected utility (EUT) is concerned with building models to explain and guide choice behavior under uncertainty in situations in which long run expected values are too simplistic. The past 40 years have seen universal applications of this theory in economics, finance, management and engineering. An outgrowth and formalized application of this theory in the early 1960's was the science of decision analysis. Decision analysis is defined by Keeney [2] as "a formalization of common sense for decision problems which are too complex for informal use of common sense".

The axioms of decision analysis provide a set of fundamental principles for analyzing decision problems. These axioms imply that the attractiveness of alternatives should depend on (1) the likelihood of possible consequences or outcomes of each alternative; and (2) the propensities of the decision makers for those consequences. The philosophical implications of the axioms are that all decisions require subjective judgments and that the likelihoods of various consequences and their desirability should be separately estimated using probabilities and utilities, respectively. The technical implications of the axioms are that probabilities and utilities can be used to calculate the expected utility of each alternative and that alternatives with higher expected utilities should be preferred by the decision maker. The practical implication of the decision analysis axioms is the provision of a sound basis and general approach for including judgments and values in an analysis of decision alternatives. This mathematical representation of decision making is well-suited for approximating individual risk propensities in the context of the organization.

\section{RISK}

Firm managers routinely face important decisions regarding the allocation of scarce capital across a set of investment opportunities - opportunities generally 
characterized by financial risk and uncertainty. Because these opportunities are often very different in terms of their risk characteristics, these decisions are conceptually difficult and generally can have significant impact on the firm's performance. The importance of risk to decision making is also confirmed by its position in decision theory [3], by its relative importance from a managerial perspective $[4,5]$, and by its increased importance in corporate risk management $[6,7]$.

In classical decision theory, risk is most commonly conceived as reflecting variation in the distribution of possible outcomes, their likelihoods and their subjective values. Risk is generally measured by either nonlinearities in the revealed utility for money or by the variance of the probability distribution of possible gains and losses associated with a particular decision alternative. Virtually all theories of choice assume that decision makers prefer larger expected returns to smaller ones, provided all other factors are constant. In general they also assume that less risk is preferred to more risk, ceteris paribus.

One cannot discuss the concept of risk without addressing the complexities associated with the decision theoretic notion of risk. Numerous biases have been documented through empirical work which establish significant differences between the normative framework and actual choice behavior. Kunreuther [8] found that individuals tend to ignore possible events that are very unlikely or very remote. There is empirical support to suggest that individuals look at only a few possible outcomes rather than the whole distribution, and measure variation with respect to those few outcomes. Allais [9] and Ellsburg [10] document specific behavioral paradoxes associated with preference reversals which are inconsistent with the axioms of rational behavior. Kahneman and Tversky's [11] seminal work in "prospect theory" specifies several classes of choice problems in which risk-taking behaviors systematically violate the axioms of expected utility. These and other descriptive studies provide useful information about cognitive processes, decision making heuristics, and decision making biases prevalent among decision makers. 
Descriptive studies of decision making behavior can provide insight into how individuals (or groups) make decisions under uncertainty, and this insight can in turn lead to prescriptive implications about how individuals can improve their decision making. In complex decision environments, such as corporate resource allocation problems, many decision makers prefer a rational and sound basis for decision making, but in fact, seriously violate the axioms of rational behavior in selecting among decision alternatives.

\section{ORGANIZATIONAL CONSIDERATIONS}

March and Shapira [12] report that observations of organizations suggest that managerial risk propensity is complex and problematic. They find that variation across individual risk propensities is seen as resulting from incentives and experience. An individual decision maker's propensity to take risk may be more aligned with his potential planning horizon within the firm. That planning horizon can be dependent on the individual's discipline and/or position in the organization. Swalm [13] found evidence that division and lower level managers are typically more risk averse than are the top managers in the organization. He also found that managers readily admit they make decisions using a risk strategy that responds to their own best career interest, rather than the best interest of their organizations. Swalm also uncovered a rather disturbing result which indicates that decision makers' utility functions appear to be more closely related to the wealth levels which they are accustomed to dealing with as individuals rather than the financial position of their companies. MacCrimmon and Wehrung [14] substantiate these findings when they found that higher level executives scored higher on their risk-taking measures than did lower level executives. The present study specifically investigates this relationship between organizational position and risk propensity.

Individual differences in risk propensity have been attributed to a general dispositional risk orientation [15], achievement orientation [16], and to the type of 
managerial position held [17]. Personal experience or beliefs about risk foster identifiable preferences in how decision makers assess and react to risk. The general argument emerging from these studies is that individuals exhibit stable differences in whether they prefer or disdain risks. They further suggest that individual risk disposition is a good predictor of what individuals' attitudes toward risk will be for a specific type of context. Although to the decision theorist it seems rather apparent to state that individuals will have a tendency to do that which they prefer to do, such a contention is far from universally accepted in the organizational literature, which generally argues that individual characteristics will be dominated by the organizational situation.

Managerial risk propensity varies across individuals and contexts. As a result we would expect to see wide variations in individual risk propensities. Much of this diversity is a result of goal conflicts between the individual and the organization. There are intrinsic motivational factors associated with risk-taking which are encoded as part of an individual's personality. An examination of differences in risk attitudes between managerial levels, as well as functional levels, (which have some relationship with personality traits) may provide further insight into risk-taking behavior.

In this research, we focus on two primary areas of investigation with regard to the potential differences in risk propensity between (1) discrete functional designations (engineering versus geoscientist); and (2) discrete managerial levels (staff, supervisor, manager) within the organization. This study measures managerial risk propensity in making corporate, rather than private decisions and then determines any significant differences along functional and managerial designation. In this study, we test the following propositions:

Proposition 1: Staff and lower level managers are more risk averse than top managers in the organizational structure. 


\section{Proposition 2: There exists no significant differences in risk propensity between individuals along functional/discipline designations, engineers versus geoscientists.}

\section{METHODOLOGY}

BP Exploration, Inc. is a subsidiary of a large multi-national integrated oil company, British Petroleum. At the time of the study, BP Exploration was actively involved in the exploration and production of oil and gas reserves onshore and offshore U.S., including Alaska, and had an annual exploration budget of approximately $\$ 300$ million. As part of this ongoing process, individuals within the firm made capital allocation recommendations and decisions based on available geological and engineering information; each decision was characterized by varying degrees of risk and uncertainty. The individual decision makers' risk propensity directly affected the capital allocation decisions and recommendations. The survey methodology utilized sets the stage for an experimental evaluation of each participating decision maker's risk propensity, within the organizational context.

EUT provides a mathematical basis for assessment of individual risk propensity and a means of mapping that risk propensity in the form of a utility function. One functional form of utility which is dominant in both theoretical and applied work in the areas of decision theory, finance and management is the exponential utility function, and is of the form $u(x)=-e^{-c x}$, where $c$ is the risk aversion coefficient, $x$ is the variable of interest, and $e$ is the exponential constant. A value of $c>0$ implies risk averse behavior, $c<0$ implies risk seeking behavior, and $c=0$ implies risk neutral behavior (expected value decision making). A thorough discussion of this functional form and its properties may be found in Keeney and Raiffa [18].

Using the exponential utility function, we then compute a risk-adjusted valuation measure for any risky or uncertain investment. This valuation measure is known as the certainty equivalent; it is defined as that certain value which a decision maker is 
just willing to accept in lieu of the gamble represented by an uncertain event. It is, in essence, the "cash value" attributed to a decision alternative which involves uncertain outcomes. Comparisons between projects are easier because they are made between a probability distribution and a certain quantity. In evaluating decision alternatives, higher certainty equivalent values are preferred to lower values, which is not always the case with expected value analysis because that measure fails to consider the individual's aversion to risky outcomes. For discrete probability distributions, the expression for certainty equivalent, $C_{X}$, has been shown by Raiffa [19] to be:

$$
c_{x}=-1 / c \ln \left(\sum_{i=1}^{n} p_{i} e^{-c x_{i}}\right)
$$

where $p_{i}$ is the probability of outcome $i, x_{i}$ is the value of outcome $i$, and $I n$ is the natural log. The certainty equivalent, $C_{X}$, is equal to the expected value less a risk discount; using the exponential utility function, the discount is determined by the individual's risk aversion coefficient, $c$, and the risk characteristics (probability distribution on outcomes) of the investment opportunity.

The approach taken both classically and by modern oil companies when evaluating uncertain drilling prospects of this sort is to assume a two-state, state-space model where the states represent success and failure, respectively. The decision that managers are confronted with is what share of the project, if any, should the firm purchase. When considering the best participation level, the decision maker scales the payoffs based on the ownership share chosen. Thus, the payoff upon success is the ownership share times the payoff of the total project upon success, and is equal to the net present value of all cash flows from the initial investment through the life of the well given that the project is successful. The total payoff upon failure is the net present value of all of the cash flows assuming the well fails. The sum of the probabilities of success and failure are equal to 1 .

Based on this two-state, state-space approach, an industry-specific questionnaire was used to evaluate the survey participants' utility functions. The questionnaire 
utilized the concepts and terminology familiar to the participants and a set of investment opportunities representative of the firm's normal decision environment. The set of "gambles" that the respondents evaluated consisted of 10 simple petroleum exploration ventures with their respective outcomes and probabilities. The EUT model is used to determine the risk propensity of the respondent, in the form of an implied utility function, by evaluating a set of realistic choices under conditions of risk uncertainty.

Figure 1 shows the format of the questions and choice options presented to the survey participants. Each of the hypothetical prospects has (1) a net present value and associated probability of success; and (2) a dry hole or risk cost and its associated probability for failure. Participants were informed that there was a linear relationship between the value of a success or dry hole outcome and the participation level in the prospect; in other words, there was no premium or discount for taking more or less of any given prospect.

FIGURE 1: UTILITY FUNCTION WORKSHEET

\begin{tabular}{|c|c|c|c|c|c|c|c|c|c|}
\hline \multirow{2}{*}{$\begin{array}{c}\text { Prospect } \\
1\end{array}$} & \multirow{2}{*}{$\begin{array}{l}\text { Outcome } \\
\text { Success }\end{array}$} & \multirow{2}{*}{$\begin{array}{c}\begin{array}{c}\text { Value } \\
\text { (\$million) }\end{array} \\
4.2\end{array}$} & \multirow{2}{*}{$\begin{array}{c}\text { Probability } \\
50 \%\end{array}$} & \multicolumn{6}{|c|}{$\begin{array}{l}\text { Choice (circle one) } \\
\text { Participation Level }\end{array}$} \\
\hline & & & & \multirow[t]{2}{*}{$100 \%$} & \multirow[t]{2}{*}{$75 \%$} & \multirow[t]{2}{*}{$50 \%$} & \multirow[t]{2}{*}{$25 \%$} & \multirow[t]{2}{*}{$12.5 \%$} & \multirow[t]{2}{*}{$0 \%$} \\
\hline & Failure & -1.4 & $50 \%$ & & & & & & \\
\hline \multirow[t]{2}{*}{2} & Success & 21.5 & $40 \%$ & $100 \%$ & $75 \%$ & $50 \%$ & $25 \%$ & $12.5 \%$ & $0 \%$ \\
\hline & Failure & -4.0 & $60 \%$ & & & & & & \\
\hline \multirow[t]{2}{*}{3} & Success & 38.0 & $10 \%$ & $100 \%$ & $75 \%$ & $50 \%$ & $25 \%$ & $12.5 \%$ & $0 \%$ \\
\hline & Failure & -3.4 & $90 \%$ & & & & & & \\
\hline \multirow[t]{2}{*}{4} & Success & 11.5 & $80 \%$ & $100 \%$ & $75 \%$ & $50 \%$ & $25 \%$ & $12.5 \%$ & $0 \%$ \\
\hline & Failure & -5.8 & $20 \%$ & & & & & & \\
\hline \multirow[t]{2}{*}{5} & Success & 6.0 & $30 \%$ & $100 \%$ & $75 \%$ & $50 \%$ & $25 \%$ & $12.5 \%$ & $0 \%$ \\
\hline & $\begin{array}{l}\text { Failure } \\
\text { Success }\end{array}$ & $\begin{array}{r}-0.8 \\
2.6\end{array}$ & $\begin{array}{l}70 \% \\
50 \%\end{array}$ & $100 \%$ & $75 \%$ & $50 \%$ & $25 \%$ & $12.5 \%$ & $0 \%$ \\
\hline 6 & Failure & -0.4 & $50 \%$ & & & & & & \\
\hline \multirow[t]{2}{*}{7} & Success & 6.2 & $15 \%$ & $100 \%$ & $75 \%$ & $50 \%$ & $25 \%$ & $12.5 \%$ & $0 \%$ \\
\hline & Failure & -1.0 & $85 \%$ & & & & & & \\
\hline \multirow[t]{2}{*}{8} & Success & 8.4 & $70 \%$ & $100 \%$ & $75 \%$ & $50 \%$ & $25 \%$ & $12.5 \%$ & $0 \%$ \\
\hline & Failure & -1.8 & $30 \%$ & & & & & & \\
\hline \multirow[t]{2}{*}{9} & Success & 7.0 & $90 \%$ & $100 \%$ & $75 \%$ & $50 \%$ & $25 \%$ & $12.5 \%$ & $0 \%$ \\
\hline & Failure & --6.0 & $10 \%$ & & & & & & \\
\hline \multirow[t]{2}{*}{10} & Success & 13.5 & $50 \%$ & $100 \%$ & $75 \%$ & $50 \%$ & $25 \%$ & $12.5 \%$ & $0 \%$ \\
\hline & Failure & -4.2 & $50 \%$ & & & & & & \\
\hline
\end{tabular}


The participant had the choice of six discrete participation options for each of the ten prospects, $100 \%, 75 \%, 50 \%, 25 \%, 12.5 \%, 0 \%$. Respondents were asked to choose the most preferred interest in each of the investment opportunities. All prospects have a positive expected value. Any choice by a respondent to participate at less than $100 \%$ implied some level of risk aversion. Given the nature of the oil industry and the prevalence of risk-sharing and joint venture agreements, this type of decision framework conformed closely to a "real-world" scenario and to the oil and gas manager's normal decision process.

In the utility function worksheet, the respondent selects the participation level preferred for each of the hypothetical drilling projects. Based on the decision maker's responses, the risk aversion coefficient, $c$, in the exponential utility function can be estimated.

Certainty equivalents were computed for each prospect selection implementing the exponential form of utility as shown in Equation 1. Consider, for example, that the respondent selects the $75 \%$ participation level in Prospect \#1. Table 1 shows a summary of the computed certainty equivalent $\left(C_{X}\right)$ values for five participation choices in Prospect \#1 at selected risk aversion coefficient levels. Note that anly the $0.30 \times 10^{-6}$ risk aversion coefficient level does the $C_{X}$ value at the $75 \%$ working interest dominate all other participation levels, in terms of the certainty equivalent valuation. Since this was the decision maker's preferred alternative for Prospect \#1 and the preferred alternative must have the highest $C_{X}$ value, we are able to imply a level of risk propensity consistent with the respondent's participation selection. By selecting the $75 \%$ option, the respondent exhibits a utility function with parameter $c$ approximately equal to $0.30 \times 10^{-6}$ (exact solution equals $0.262 \times 10^{-6}$ ). For each prospect and participation level, the associated risk aversion coefficient is computed in this way. Findings from each questionnaire are aggregated in order to compare risk propensity by functional and managerial designation. 


\begin{tabular}{|c|c|c|c|c|c|}
\hline \multirow[b]{2}{*}{$\begin{array}{l}\text { Risk Aversion } \\
\text { Coefficient }(c)\end{array}$} & \multicolumn{5}{|c|}{ Prospect \#1 - Certainty Equivalent Valuation, $C_{x}$ (\$millions) } \\
\hline & $100 \%$ W.I. & 75\% W.I. & $50 \%$ W.I. & $25 \%$ W.I. & $12.5 \%$ W.I. \\
\hline $0.001 \times 10^{-6}$ & 1.396 & 1.048 & 0.699 & 0.350 & 0.175 \\
\hline $0.01 \times 10^{-6}$ & 1.361 & 1.028 & 0.690 & 0.348 & 0.174 \\
\hline $0.05 \times 10^{-6}$ & 1.205 & 0.940 & 0.651 & 0.338 & 0.172 \\
\hline $0.10 \times 10^{-6}$ & 1.013 & 0.831 & 0.602 & 0.326 & 0.169 \\
\hline $0.20 \times 10^{-6}$ & 0.654 & 0.621 & 0.507 & 0.301 & 0.163 \\
\hline $0.30 \times 10^{-6}$ & 0.341 & 0.428 & 0.414 & 0.277 & 0.157 \\
\hline $0.40 \times 10^{-6}$ & 0.800 & 0.256 & 0.327 & 0.253 & 0.151 \\
\hline $0.50 \times 10^{-6}$ & -0.132 & 0.105 & 0.245 & 0.230 & 0.145 \\
\hline $0.80 \times 10^{-6}$ & -0.548 & -0.226 & 0.040 & 0.163 & 0.127 \\
\hline $1.00 \times 10^{-6}$ & -0.711 & -0.372 & -0.066 & 0.123 & 0.115 \\
\hline
\end{tabular}

Table 1. Certainty equivalent $\left(C_{x}\right)$ analysis for Prospect \#1 at selected risk aversion coefficients. The selection of the $75 \%$ working interest (W.I.) participation level by the respondent implies a $c$ coefficient of $0.30 \times 10^{-6}$ since it is at that risk propensity that the $75 \%$ interest dominates all other participation levels in terms of the $C_{x}$ value.

The survey questionnaire was prepared and distributed to a cross-section of 39 petro-technical employees of the corporation. Descriptive personal information was requested from each participant to allow evaluation of preferences and variances between sub-grouping by both managerial position (staff, supervisor or manager) and discipline (engineer or geoscientist). Each participant was instructed to select, based on the probabilities and discounted values given, a participation level which they would recommend to senior management. Each participant was requested to return the survey within 10 days. Comments which ensured confidentiality and stated that there were no "correct" answers were included in the instructions to alleviate any anxiety over completing the survey.

\section{Data analysis and results}

Of the 39 surveys distributed, we received responses from 36 individuals. Each response was analyzed by using Equation 1, where we solve for the implied risk aversion coefficient, $c$, for each investment choice made by the respondent. We computed conventional means of the implied $c$ coefficients from each investment choice to approximate each respondent's utility function. The zero and $100 \%$ participation selections were not utilized in the analysis since they represent 
unbounded solutions for the risk aversion coefficient, $c .^{1}$ For example, in Prospect No. 6 , the selection of $100 \%$ participation implies a $c$ coefficient less than or equal to $0.624 \times 10^{-6}$, which tells us little about the decision maker's risk propensity. We compute each of the respondents' exhibited risk propensities in this way. Tables 2-A and 2-B provide a summary of the statistical parameters based on the computed risk aversion coefficients for all respondents.

\begin{tabular}{|l|cc|}
\hline \multicolumn{3}{|c|}{\begin{tabular}{l}
\multicolumn{2}{c|}{ Risk Propensity by Discipline } \\
Risk Aversion Coefficient (c)
\end{tabular}} \\
Respondents & Engineers & Geoscientists \\
& 21 & 15 \\
Minimum & Risk Aversion Coefficient. (c) \\
Maximum & $0.120 \times 10^{-6}$ & $0.160 \times 10^{-6}$ \\
Mean & $0.419 \times 10^{-6}$ & $0.416 \times 10^{-6}$ \\
Std. Deviation. & $0.216 \times 10^{-6}$ & $0.306 \times 10^{-6}$ \\
\hline
\end{tabular}

Table 2-A: Risk propensity by Discipline

Table 2-A summarizes the statistical parameters on the basis of discipline (engineers and geoscientists) and Table 2-B summarizes the results on the basis of position (staff, supervisor and manager).

\begin{tabular}{|c|c|c|c|}
\hline \multicolumn{4}{|c|}{ Risk Propensity by Position } \\
\hline \multicolumn{4}{|c|}{ Risk Aversion Coefficient (c) } \\
\hline & Staff & Supervisors & Managers \\
\hline \multirow[t]{2}{*}{ Respondents } & 19 & 9 & 7 \\
\hline & \multicolumn{3}{|c|}{ Risk Aversion Coefficient. (c) } \\
\hline Minimum & $0.132 \times 10^{-6}$ & $0.132 \times 10^{-6}$ & $0.126 \times 10^{-6}$ \\
\hline Maximum & $0.416 \times 10^{-6}$ & $0.375 \times 10^{-6}$ & $0.385 \times 10^{-6}$ \\
\hline Mean & $0.289 \times 10^{-6}$ & $0.213 \times 10^{-6}$ & $0.228 \times 10^{-6}$ \\
\hline Std. Deviation. & $0.083 \times 10^{-6}$ & $0.081 \times 10^{-6}$ & $0.109 \times 10^{-6}$ \\
\hline
\end{tabular}

Table 2-B: Risk Propensity by Position

\footnotetext{
${ }^{1}$ As one anonymous reviewer notes, excluding the $100 \%$ participation choices may bias the risk aversion results upward since the $100 \%$ choice represents a lower implied risk aversion. However, since only 11 of the 331 observations were the $100 \%$ participation choice, this had no significant impact on our results.
} 
We test our propositions for differences in risk propensity by discipline and position using a pairwise comparison methodology. We test for statistically significant differences in the implied risk aversion coefficient, $c,(1)$ between geologists and engineers; and (2) among staff, supervisors and managers. Pairwise comparisons were made using student $t$ techniques at the $99 \%$ significance levels. Table 3 presents the results of these tests.

\begin{tabular}{|c|c|c|c|c|}
\hline \multirow{4}{*}{$\begin{array}{l}\text { DISCIPLINE } \\
\text { Geologist - Engineer } \\
\text { POSITION } \\
\text { Staff - Supervisor } \\
\text { Staff - Manager } \\
\text { Supervisor - Manager }\end{array}$} & \multicolumn{3}{|c|}{$\begin{array}{c}\text { Pairwise Comparisons } \\
\text { Risk Aversion Coefficient, c } \\
\text { Discipline and Position }\end{array}$} & \multirow[b]{2}{*}{$\begin{array}{l}\text { Statistical } \\
\text { Significance }\end{array}$} \\
\hline & Difference & $t$-statistic & $\begin{array}{c}\text { Significant at } \\
0.01 \text { (t - } \\
\text { value) }\end{array}$ & \\
\hline & $0.090 \times 10^{-6}$ & 6.211 & 2.750 & Yes \\
\hline & $\begin{array}{r}0.076 \times 10^{-6} \\
0.061 \times 10^{-6} \\
-0.015 \times 10^{-6}\end{array}$ & $\begin{array}{r}5.598 \\
4.363 \\
-0.554\end{array}$ & $\begin{array}{l}2.492 \\
2.508 \\
3.012\end{array}$ & $\begin{array}{l}\text { Yes } \\
\text { Yes } \\
\text { No }\end{array}$ \\
\hline
\end{tabular}

Table 3: Pairwise Comparisons

It is also useful to look at the interaction between the two variables of interest, functional and managerial designation and to explore for any possible cross effects. Table 4 provides a summary of the measured risk aversion levels for each combination of functional and managerial designation.

Utilizing a two-way ANOVA test with interaction, there exists no statistically significant interaction between the two variables of interest, managerial and functional designation. In other words, risk propensity differences between staff and supervisors and staff and managers (as shown in Table 2) is not statistically related to functional background. In addition, our statistical analysis indicates risk propensity differences between geologists and engineers is not statistically related to managerial designation. 


\begin{tabular}{|l|ccc|}
\hline \multicolumn{4}{|c|}{ Risk Aversion Coefficient, c } \\
Combined Managerial and Functional Designation \\
Geologist & Staff & Supervisor & Manager \\
Engineer & $0.355 \times 10^{-6}$ & $0.261 \times 10^{-6}$ & $0.211 \times 10^{-6}$ \\
& $0.189 \times 10^{-6}$ & $0.204 \times 10^{-6}$ & $0.240 \times 10^{-6}$ \\
\hline
\end{tabular}

Table 4: Risk Aversion Coefficient

\section{Discussion and implications}

Previous research has examined the differences in risk attitudes across managerial levels in the organization. This study partially supports some of those prior findings. With regard to the differences in risk propensity between staff and supervisors, as well as staff and managers, data in Table 3 indicate that there is a statistically significant difference using a single tailed student $t$ test. This suggests that that there is support for Proposition \#1, that lower level staff exhibit higher risk aversion levels than supervisory or managerial level employees. The difference between supervisor and manager designation shows no statistically significant difference in risk propensity, as measured by the risk aversion coefficient. An important implication of this finding is that highly risk averse behavior by lower-level staff may result in a "screening out" of risky projects where senior management might otherwise be willing to participate. Lower level staff may be too conservative because they use their own outcomes (e.g., promotion, loss of job) rather than the company's outcomes (e.g., net present value) as the basis for decisions. Staff-level employees may reject all proposals but the low-risk, low-gain type and top decision makers may never get to rule on many potentially desirable investments which may be consistent with the "corporate" risk propensity.

As shown in Table 3, the two-tailed student $t$ test rejects Proposition \#2. Our sample results reject the proposition that there are no differences in risk propensity of individuals along functional/discipline designations. Rejection of this proposition would support earlier work that shows that individual differences in risk preference can be attributed to a general dispositional risk orientation or intrinsic motivational factors associated with risk-taking which are encoded as part of an individual's 
personality. The presence of significant differences in risk propensity across disciplines, within a single corporate structure, may suggest a failure on the part of management to communicate a consistent organizational risk policy. Choice behaviors change when attention turns from the behavior of isolated individuals to the behavior of those individuals within the organizational context. When people assume organizational positions, they adapt their goals and responsibilities. Those goals and responsibilities affect the particular risk propensities exhibited by the individual in the organizational context.

These findings of risk propensity differences between managerial and functional levels have important implication in terms of managing the corporation. Implementing organizational risk management strategies can go a long way towards effective and consistent decision making. Organizing and motivating employees to take prudent risks can be accomplished by communicating a coherent organizational risk policy and developing a compensation and incentive structure that is consistent with an environment of risky decision making. Managers must be at least partially evaluated on the basis of their decisions, rather than on the basis of outcomes. Making the distinction between decision and outcome allows us to separate action from consequence - and hence improve the quality of action. This type of organizational process (1) requires a more sophisticated personnel evaluation system; (2) encourages documentation of the basis of decisions at the time they are made, and before the outcomes are known; and (3) encourages more group decision making, and the responsibility for risky decisions is shared.

Several limitations of this study should be acknowledged. Gaining access to decision makers within a firm such as BP and providing "real-world" scenarios for analysis remains difficult for researchers in decision choice behavior. Firms' reluctance to participate in such studies generally are related to the cost of the undertaking as well as the compromise of confidentiality. Also, an underlying assumption of this study was that the mean of the respondent's implied $c$ coefficients for each project choice represented the respondent's exhibited risk propensity. 
Moreover, the mean of the particular group (staff, supervisor, engineer, etc.) was assumed to represent the risk propensity of that position or discipline. This assumption is particularly open to criticism. Not only does it mean that executives compromise, but that the degree of compromise is given by the average. Notwithstanding the limitations of this type of analysis, this study represents a substantial improvement over previous research of risk-taking which has tended to use settings that are unrealistic and far removed from the actual risks firms face, and those studies have usually been conducted with students as subjects. Indeed the overall results of this study generate some rather robust findings and stimulate some interesting risk policy questions for the organization.

\section{REFERENCES}

[1] von Neumann, J. and Morgenstern, O., Theory of Games and Economic Behavior. Princeton University Press, Princeton, New Jersey, 3rd Edition (1953).

[2] Keeney, R.L. "Decision Analysis:An Overview", Operations Research, 30:803-808 (1982).

[3] Arrow, K.J., Aspects of the theory of risk bearing. Helsinki: Yrjo Jahnssonis Saatio (1965).

[4] MacCrimmon, K.R. and D.A. Wehrung, Taking Risks: The Management of Uncertainty. The Free Press, New York, NY (1986).

[5] Shapira, Z., Risk Taking: A Managerial Perspective. Russell Sage Foundation, New York, NY (1995).

[6] Howard, Ronald A., Decision analysis: practice and promise, Management Science, Vol. 34, No. 6: 679-695 (1988). 
[7] Spetzler, C.S., The Development of a Corporate Risk Policy for Capital Investment Decisions. IEEE Transactions on Systems Science and Cybernetics Institute of Electrical and Electronics Engineers SSC-4 (1968).

[8] Kunreuther, H., "Limited knowledge and insurance protection", Public Policy, Vol. 24, pp. 227-261 (1976).

[9] Allais, M., "The foundations of a positive theory of choice involving risk and a criticism of the postulates and axioms of the American school", Expected Utility Theory and the Allais Paradox (1979).

[10] Ellsburg, D., "Risk, ambiguity and the Savage axioms", Quarterly Journal of Economics, vol. 75, pp. 643-669 (1961).

[11] Kahneman, D. and Tversky, A., "Prospect theory: an analysis of decision under risk", Econometrica vol. 47, pp 263-291 (1979).

[12] March, J.G. \& Shapira, Z., Managerial Perspectives on Risk and RiskTaking, Management Science, 33:1404-1418 (1987).

[13] Swalm, R.O., Utility theory-insights into risk taking. Harvard Business Review 44, 123-136 (1966).

[14] MacCrimmon, K. and Wehrung, D., Taking Risks: The Management of Uncertainty, Free Press, New York (1986).

[15] Kogan, H. and Wallach, M.A., Risk Taking: A Study in cognition and Personality, Holt, Rinehart \& Winston, New York (1964).

[16] McClelland, D.C., The Achieving Society, Princeton: Van Nostrad (1961). 
[17] Brockhaus, R.H., "Risk-taking propensity of entrepreneurs", Academy of Management Journal, vol. 23, pp. 509-520 (1980).

[18] Keeney, R.L. \& Raiffa, H., Decisions with Multiple Objectives: Preferences and Value Tradeoffs. John Wiley \& Sons, New York (1976).

[19] Raiffa, H., Decision Analysis: Introductory Lectures on Choices Under Uncertainty. Reading, Mass: Addison-Wesley, (1968). 